\title{
Virtual Community for Adults with Developmental Disabilities and their Families
}

\author{
Susan D. Moisey \\ Athabasca University
}

Adults with developmental disabilities in Northeast Alberta, Canada, face numerous barriers to learning opportunities within their immediate and extended communities. The disability itself, as well as geographic distance and the circumstances in which individuals live, may hamper their access to information, interfere with their ability to communicate, and reduce their ability to achieve the quality of life they desire. There are few opportunities for individuals to meet, to get to know each other, and to share their experiences and learn from each other. Family members and guardians face similar barriers, such as lack of access to information, few networking opportunities, and limited means of providing input into decisions about service needs and policy making.

The Northeast Alberta Virtual Community for Adults with Developmental Disabilities and their Families addresses these barriers, forming a model for community development in a rural setting. Integrating distance education communication and information technologies in an accessible website, this project creates a virtual community where adults with developmental disabilities in Northeast Alberta and their families/ guardians can meet with each other as well as with service providers, community groups, policy makers, and advocates. Communication and information technology combined with local community-based resources provide a means where information may be easily accessed, where support may be given and received, where advice and experience may be shared, and where hope and dreams may be developed and realized.

The vision is a highly accessible virtual community or 'meeting place,' where individuals interact with each other in a mutually supporting manner, offering advice, encouragement, and friendship. They readily access information about local support services, and engage in discussions with service providers. If services are not available or suitable, they contact advocates or policy makers to communicate their unmet needs. The community is dynamic, providing up-to-date information about developments, opportunities, and local achievements as they occur. Access to high quality information and increased communication opportunities may enhance the ability of persons with developmental disabilities and their families to be well informed, to make their needs and views known, and to participate in community-based policy and decision-making. Used properly, online communication and information technology are important enabling 
technologies (i.e., electronic curb-cuts) for people with disabilities, increasing their access to and their ability to participate in an increasingly knowledge-based society.

\section{Goals and Objectives}

The project aims to achieve the following goals:

- To examine how individuals with developmental disabilities (as well as their families, guardians, and others involved in their life) access Web-based information to make choices and improve their quality of life in areas, such as the following: housing, employment, leisure, support services, education.

- To investigate how individuals with developmental disabilities (as well as their families, guardians, and others involved in their life) use Web-based communication technologies to build and maintain contact with a social support network, express views, share experiences, and provide input into policy and decision-making processes.

To support these goals, the following project objectives have been identified:

1. To develop an accessible website that provides information to support decision-making and fosters communication among community members. Website accessibility is defined broadly and includes the following: information is provided at Grade 6 reading level; site is accessible by screen reader software; facilitators are available to explain/ assist with access to website; and there is suitable promotion to ensure community awareness of website.

2. To promote community-wide Internet access throughout Northeastern Alberta using the Community Access Points (CAP sites) network. Alberta North has established and funded 20 educational technology centres in Northeastern Alberta. Workstations in these sites will be upgraded with text reader software, and staff will be trained to facilitate online communication.

3. To develop appropriate supports so that adults with developmental disabilities in Northeastern Alberta can engage in their virtual community to the extent they choose. Supports include ensuring availability of computer technology and Internet connectivity, and training for service provider staff in how to teach/ facilitate Internet use for individuals with developmental disabilities and their families.

\section{Project Partners}

The project is supported by a grant from the Office of Learning Technologies, Human Resources Development Canada through their program, 'New Practices in Learning Technologies.' This collaborative project involves the following partners:

- Centre for Distance Education, Athabasca University

- $\quad$ Alberta North

- $\quad$ Northeast Alberta Community Board for Persons with Developmental Disabilities 
- $\quad$ Alberta Association for Community Living

For more information on the Northeast Alberta Virtual Community for Adults with Developmental Disabilities and Their Families, visit our project website at AU's Centre for Distance Education.

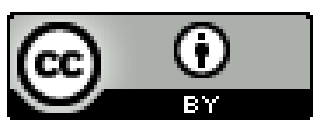

